\title{
Study of microwave hydrothermal production of lactic acid from seaweed-derived alginate using a response surface methodology based on the Box-Behnken design
}

\author{
Roman Rodríguez-Maecker ${ }^{1,}$, , Isabel Pazmiño-Mayorga ${ }^{1}$, Jessenia López-Ortega ${ }^{1}$, Liseth Chacón- \\ Molina ${ }^{1}$ and Eduardo Vyhmeister ${ }^{2}$ \\ ${ }^{1}$ Departamento de Ciencias de la Energía y Mecánica, Carrera de Petroquímica, Universidad de las Fuerzas \\ Armadas - ESPE, Latacunga, Ecuador \\ ${ }^{2}$ Insight Research Centre for Data Analytics, University College Cork, Cork, Ireland
}

\begin{abstract}
A microwave hydrothermal treatment was used for the chemical production of lactic acid from alginate extracted from the brown seaweed Padina Durvillaei, collected in the coastal area of Ecuador. The microwave hydrothermal treatment was studied through a response surface methodology based on the Box-Behnken design, using temperature, reaction time, and catalyst concentration as the manipulated variables and the yield as a response factor. The characterization of alginate was performed by Fourier Transform Infrared Spectroscopy (FTIR), Differential Scanning Calorimetry (DSC) and Thermogravimetric Analysis (TGA). The lactic acid produced was quantified using Gas Chromatography - Ion Mobility Spectrometry (GC-IMS). The results show that temperature and catalyst concentration played the most critical roles in alginate extraction and lactic acid production. The optimal experimental conditions for alginate extraction from brown seaweed were: temperature $=92.91^{\circ} \mathrm{C}$, time $=110.81 \mathrm{~min}$ and catalyst $\left(\mathrm{Na}_{2} \mathrm{CO}_{3}\right)$ concentration $=2.60 \%$, with a yield $=29.19 \%$. Although the experimental evidence indicates a positive influence of microwaves' use on the production of lactic acid from alginate through hydrothermal treatment, a new study considering temperatures above $220^{\circ} \mathrm{C}$ and reaction times below 60 min should be developed.
\end{abstract}

Keywords: Microwave hydrothermal production; alginate; lactic acid; seaweed; response surface methodology; Box-Behnken design.

\section{Introduction}

Lactic acid (2-hydroxypropionic acid) is a commodity chemical that was discovered in 1780 from sour milk ${ }^{1}$. Industrial production of this natural organic acid started in 1881 with several applications in food, cosmetic, pharmaceutical, and chemical industries ${ }^{2-4}$. Lactic acid (LA) is also used as a feedstock monomer for chemical conversion to obtain oxygenated compounds and polymers. One of the promising uses of LA is the manufacture of polylactic acid (PLA), a biodegradable polymer used for packaging, medical applications, 3D printing, and textile and pharmaceutical industries ${ }^{5-9}$. According to recent market research, the worldwide market of LA will be worth more than six billion dollars by 2024, where PLA production is the most significant application ${ }^{10}$. Hence, the growing demand for LA will continue, and new processes and resources need to be explored to satisfy current and future applications.

Mass production of LA is mainly carried out through biotechnological pathways. The conventional

*Corresponding author: Roman Rodríguez-Maecker Email address: rnrodriguez@espe.edu.ec DOI: http://dx.doi.org/10.13171/mjc10802008241482rrm feedstock includes biomass waste, wood, whey, molasses, and cornstarch. The study of enhanced substrates, new fermentation techniques, and unconventional microorganisms looks to improve LA yield. However, processing time and expensive microorganisms represent challenges to be overcome ${ }^{11-14}$. On the other hand, LA can also be obtained through chemical synthesis. One of the mechanisms consists of oxidation of propylene with nitric acid, but the main drawback is related to the dependence on petrochemical feedstock ${ }^{15}$. Another chemically driven mechanism is the hydrothermal treatment of renewable resources such as biomass and its derivatives. Specifically, from seaweed, lactic acid and many other valuable products can be obtained: formic acid, acetic acid, malic acid, fumaric acid, succinic acid, glycolic acid, furfural, among others ${ }^{16-19}$.

Alginate is an anionic copolymer formed by blocks of $\beta$-D-mannuronic acid (M block) and $\alpha$-L-guluronic acid ( $\mathrm{G}$ block) arranged in an irregular fashion of

Received May 24, 2020

Accepted July 8, 2020

Published August 24, 2020 
varying proportions of both blocks ${ }^{20,21}$. Alginate is naturally found in the brown seaweed cell walls, which constitutes the primary source of commercial isolation of alginate ${ }^{22,23}$. The usual carbohydrate composition of representative brown seaweed indicates that alginate is the most abundant polysaccharide, and that lignin presents low concentrations. Hence, alginate extraction and conversion are facilitated. The alginate structure allows the production of valuable chemicals such as bioethanol, furfural, and organic acids through acid or base-catalyzed reactions ${ }^{24,25}$. Also, brown seaweed constitutes a potential next-generation feedstock for biorefinery due to their abundance in water bodies around the world, their potential to absorb $\mathrm{CO}_{2}$, their high growth rate, their minor land occupancy, and their capability to form multiple products ${ }^{26-28}$.

Hydrothermal treatment (HTT), a process that consists of applying heat and pressure in an aqueous medium, can be used in subcritical and supercritical conditions (for water: $374^{\circ} \mathrm{C}$ and $22.1 \mathrm{MPa}$ ), considering operational requirements such as temperature, time, particle size and water-to-solid biomass ratio. HTT has been applied mainly to lignocellulosic materials, where changes are induced into the structure of the cell wall. Hence, the fractionation of the cell wall occurs due to the selfionizing property of water $\left(\mathrm{H}_{3} \mathrm{O}^{+}\right.$and $\left.\mathrm{OH}^{-}\right)$. This characteristic causes water to act as a catalyst that leads to hydrolysis and depolymerization processes without external catalysts ${ }^{29}$. Examples of noncatalyzed HTT are Liquid Hot Water (LHW) and Steam Explosion (SE) techniques. In LHW, the application of high pressure keeps water in a liquid state at high temperatures and in contact with the biomass. This causes solvolysis and dissolves up to $22 \%$ of cellulose, $60 \%$ of lignin, and $100 \%$ of hemicellulose. In SE, the biomass is rapidly heated using high-pressure steam. After some time, the biomass-steam mixture undergoes hydrolysis. Finally, the steam is released through explosive decompression, which reduces temperature quickly and generates a rapid expansion that causes the particulate structure of biomass to open ${ }^{30}$. HTT is an alternative for the fractionation of seaweed because of the excellent solvent properties of water as a reaction medium. In addition, the high moisture content of macroalgae makes HTT a promising processing technology for the direct use of macroalgae in the production of biofuels and compounds with high added value. In the case of brown algae, which contain sulfated polysaccharides, the hydrolysis caused by the application of HTT generates a drop in $\mathrm{pH}$, contributing to an effective self-catalyzed process ${ }^{31}$.

The use of seaweed as a raw material has several advantages, such as low fluctuations in demand for biomass due to overpopulation and high availability.
This is due to rapid growth in the open ocean, higher photosynthetic activity related to terrestrial biomass, low recollection costs, and no environmental damage. However, research on the application of HTT to seaweed is limited. On the other hand, the use of microwaves as an alternative heating source has been successfully applied to extract numerous compounds from a wide variety of natural resources, since it is characterized by a selective, efficient, and environmentally friendly process. The microwave technique involves a rapid supply of energy to the entire reaction volume, which causes rapid heating and accelerates the solubilization of compounds. Polar solvents such as water have a permanent dipole moment, absorb microwave radiation, and transfer it effectively to the sample. It also has an advantage over organic solvents, to be a safe and ecological reagent. Microwave-assisted HTT is a technique that should be considered for the extraction of seaweed polysaccharides since the main polysaccharides present in macroalgae (laminarin and fucoidans) are water-soluble compounds ${ }^{32}$.

The present work describes a comprehensive process for brown seaweed treatment to alginate extraction and lactic acid production, along with the analytical methods used to monitor the products on both steps.

\section{Material and methods}

The brown seaweed (Padina Durvillaei) were collected in the coastal area of Ecuador, washed with distilled water, dried at $50^{\circ} \mathrm{C}$ for 24 hours in a vacuum oven (Binder, Germany), ground in a food processor (UMCO, USA). There were then sieved with a mesh 40 , which allows the passage of particles smaller than 420 um (Retsch, USA) and stored in dark polypropylene bags until treatment. All chemical reagents were analytical grade. The response surface graphs were obtained using Statgraphis Centurion 16.1.03 software.

\subsection{Experimental planning}

The procedure to obtain lactic acid was carried out using two main steps: 1) extraction of alginate from brown seaweed; and 2) production of lactic acid from extracted alginate. The experimental variables that influenced each stage were analyzed by applying a Response Surface Methodology (RSM), using the second-order model known as the Box-Behnken design (BBD), with three factors, three levels per factor and three central point's ${ }^{33}$. The experimental factors were temperature, reaction time, and catalyst concentration, as summarized in Table 1. The response variable evaluated was the yield of alginate for step 1, and the yield of lactic acid for step 2. The combination of factors and levels defined by the software are indicated in Table 2 for alginate extraction, and in Table 3 for lactic acid production. 
Table 1. Variables and levels for alginate extraction from seaweed and lactic acid production from alginate.

\begin{tabular}{|c|c|c|c|c|}
\hline \multirow{2}{*}{ Step } & \multirow{2}{*}{ Factor } & \multicolumn{3}{|c|}{ Level } \\
\hline & & -1.000 & 0.000 & +1.000 \\
\hline \multirow{3}{*}{$\begin{array}{l}\text { Alginate } \\
\text { extraction }\end{array}$} & Temperature $\left({ }^{\circ} \mathrm{C}\right), \mathrm{T}$ & 80 & 90 & 100 \\
\hline & Reaction time (min), t & 60 & 90 & 120 \\
\hline & Catalyst concentration $(\%), \mathrm{C}$ & 2.0 & 2.5 & 3.0 \\
\hline \multirow{3}{*}{$\begin{array}{l}\text { Lactic acid } \\
\text { production }\end{array}$} & Temperature $\left({ }^{\circ} \mathrm{C}\right), \mathrm{T}$ & 180 & 200 & 220 \\
\hline & Reaction time (min), $\mathrm{t}$ & 30 & 60 & 90 \\
\hline & Catalyst concentration (\%), C & 0.0 & 2.0 & 4.0 \\
\hline
\end{tabular}

\subsection{Alginate extraction and characterization}

The extraction of alginate was performed over a $1.0 \mathrm{~g}$ sample of brown seaweed particles previously washed, dried, ground, and sieved. First, removal of counterions was carried out using $\mathrm{HCl} 2.0 \mathrm{M}$ over 24 hours and subsequent washing with distilled water. The resulting biomass was placed inside a reactor with $30 \mathrm{ml}$ of catalyst $\left(\mathrm{Na}_{2} \mathrm{CO}_{3}\right)$ solution at $\mathrm{pH} \approx 11.90 \pm 0.10$ and digested with a microwave system equipped with an unpulsed regulated $2.45 \mathrm{GHz}$-magnetron which provides up to $1450 \mathrm{~W}$ (Topwave, Analytik Jena, Germany). Operating conditions were varied following the experimental design previously described. The liquid product containing the alginate was collected and centrifuged (C-28A, Boeco, Germany) for 15 minutes at $4000 \mathrm{rpm}$ to remove particulates. The supernatant was recovered and mixed with $60 \mathrm{ml}$ of ethanol (96\%) to precipitate the alginate. Finally, the solid alginate was dried, crushed, and stored in a dark glass bottle. The yield was calculated by relating the weight of extracted alginate and the initial seaweed amount used. Fourier Transform Infrared Spectroscopy (FTIR) (Frontier, Perkin Elmer, USA) was used to obtain a spectrum from 4000 to $600 \mathrm{~cm}^{-1}$. The reference spectrum of alginate obtained from a standard sample (Sigma Aldrich, USA) was used to examine the various spectra of extracted alginate. The ratio mannuronate (M)/guluronate $(\mathrm{G})$ was determined considering the intensity of the FTIR characteristics bands of mannuronic acid and guluronic acid at $1025 \mathrm{~cm}^{-1}$ and $1080 \mathrm{~cm}^{-1}$, respectively ${ }^{34}$. The ratio mannuronate $(\mathrm{M})$ /guluronate (G) is indicative of the type of gel that alginate can form: $M / G>1$ produces soft and elastic gels while $\mathrm{M} / \mathrm{G}<1$ produces strong and rigid gels ${ }^{35}$. The heating rate used in differential scanning calorimetry (DSC 1, Mettler Toledo, Switzerland) was from $25^{\circ} \mathrm{C}$ to $550^{\circ} \mathrm{C}$ at $10^{\circ} \mathrm{C} / \mathrm{min}$ with a nitrogen flow rate of $90 \mathrm{ml} / \mathrm{min}$. The thermogravimetric analysis (Pyris 1, Perkin Elmer, USA) used a heating rate from $25^{\circ} \mathrm{C}$ to $900^{\circ} \mathrm{C}$ at $10^{\circ} \mathrm{C} / \mathrm{min}$ with a nitrogen flow rate of $20 \mathrm{ml} / \mathrm{min}$.

\subsection{Lactic acid production and quantification}

The hydrothermal reaction over $1.0 \mathrm{~g}$ of alginate to produce lactic acid was carried out in a microwave system (Topwave, Analytik Jena, Germany). The solid catalysts used was calcium oxide, which was previously sieved with a mesh 40 and activated at $500^{\circ} \mathrm{C}$ for 5 hours in a muffle (Thermolyne, Thermo Scientific, USA). The catalyst $(\mathrm{CaO})$ and alginate were placed in a reactor with $30 \mathrm{ml}$ of distilled water. The final solutions with catalyst presented a $\mathrm{pH} \approx 12.30 \pm 0.10$ while the final solutions without catalyst presented a $\mathrm{pH} \approx 8.40 \pm 0.10$. The operating conditions used for the hydrothermal reaction were described in the experimental planning section. After the reaction time ended, the reaction mixture's $\mathrm{pH}$ was conditioned using $\mathrm{HCl} 2.0 \mathrm{M}$ until reaching a $\mathrm{pH}$ of 1.5. The non-dissolved catalyst after the addition of $\mathrm{HCl}$ was recovered by centrifugation at $4000 \mathrm{rpm}$ for 15 minutes. A final filtration step removed the solid particles, and the remaining solution containing lactic acid was stored for analysis.

Lactic acid identification and quantification were carried out directly on the sample solution using Static Headspace Gas Chromatography - Ion Mobility Spectrometry (SHS GC-IMS), a powerful technique with several advantages: low detection limits, good selectivity, fast analysis time and no need for sample pretreatment. SHS GC-IMS performs the determination of three parameters: retention time (Rt) of analytes in the gas chromatograph, drift time (Dt) of ions in the ion mobility spectrometer, and amount of compound (signal intensity recorded by the detector). These parameters are represented in a threedimensional graphics called topographic spectra, which are used for identification and quantification. All topographic spectra were normalized relative to the reaction ion peak (RIP) drift time, to avoid the influence of the pressure and temperature deviations between the measurements $\left(\mathrm{Dt}_{[\mathrm{RIP}]}=1\right)^{36}$.

The SHS GC-IMS used was a Flavourspec (G.A.S., Germany), with a SE-54 stationary phase column ( $15 \mathrm{~m} \mathrm{x} 0.25 \mathrm{~mm}$ ID) operated isothermally at $40^{\circ} \mathrm{C}$, using $\mathrm{N}_{2}$ as carrier gas with a flow rate of

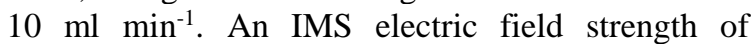

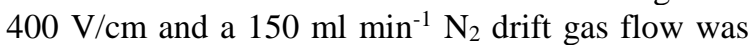
applied in a drift tube of $50 \mathrm{~mm}$ length and operated at $75^{\circ} \mathrm{C}$. The IMS ionization source was tritium $3 \mathrm{H}$ ( $\beta$ radiation) of $300 \mathrm{MBq}$ with average radiation 
energy of $5.68 \mathrm{keV}$. Lactic acid analytical standard (Sigma Aldrich, USA) was used for identification and quantification, based on a calibration curve. $1.0 \mathrm{ml}$ of lactic acid solutions (standards and samples) were placed individually in a 20-ml-headspace glass vial, which was immediately gas-tight sealed with a polytetrafluoroethylene septum and a magnetic lid cap. The glass vials were placed in a 32 positions headspace autosampler (Combi Pal, CTC Analytics AG, Switzerland) equipped with an incubator-agitator and a heated $\left(50^{\circ} \mathrm{C}\right)$ gas-tight 1-mL-syringe (Hamilton, Switzerland). Before the analysis, the vials were equilibrated for 3 minutes at $75^{\circ} \mathrm{C}$ under constant agitation at $500 \mathrm{rpm}$. $1000 \mu \mathrm{l}$ of the headspace was automatically injected into the GCIMS and analyzed, as indicated previously by quintuplicate. Each IMS spectrum was recorded in the positive mode.

\section{Results and Discussion}

\subsection{Alginate extraction from brown seaweed}

The effect of temperature and time (Fig. 1a) shows that increasing the temperature and time, the yield of extracted alginate is also increased, up to the optimum temperature value $\left(92.91{ }^{\circ} \mathrm{C}\right)$. After this point, the yield of extracted alginate decreases. The observed behavior could be attributed to the fact that, at low temperatures, there is not enough energy to drive the interaction of reactants, while at higher temperatures, both reactants and products can decompose. When analyzing the reaction time, alginate extraction increases with time until reaching the maximum point (110.81 $\mathrm{min})$, where it tends to stabilize, which suggests that the course of time does not influence the alginate extraction process after this point. The effect of the reaction time on the extraction of alginate is corroborated by analyzing the effect of time vs. catalyst concentration (Fig. 1b), where at the highest time values, there is even a small decrease in the yield of extracted alginate. This can be interpreted as a point where the alginate begins to decompose. The effect of catalyst concentration on the extraction of alginate shows that the presence of a catalyst at higher concentrations increases the yield of alginate to the maximum value, where it tends to decrease. This observation may be associated with a higher concentration of solutes in a solution, which inhibits the extraction process due to saturation. This behavior can also be observed on the correlation effect of temperature vs. catalyst concentration (Fig. 1c). Here, at low temperature and low catalyst concentration, the extracted alginate yield is significantly smaller than the amount of alginate obtained at higher temperatures and higher catalyst concentrations. Therefore, the effect of temperature and catalyst concentration on the extraction process of alginate from seaweed is crucial.

From the analysis of variance for alginate extraction (Table 2), it is evident that the three variables, temperature, time, and catalyst, present a markable effect, because all variables offer a p-value lower than 0.05 , being the time the most important one. It would have been essential to test the effect on alginate extraction without using any catalyst at this point, but this was not considered in the original approach of the study. The $p$-value $=0.3945$ for lack of fit indicates it is not significant, and therefore, the second-order model by the Box-Behnken design could also fit a linear model. The regression coefficient $\mathrm{R}^{2}=0.9840$ indicates a good correlation between the experimental results and the predicted values. The difference between the adjusted $\mathrm{R}^{2}=0.9555$ and the predicted $\mathrm{R}^{2}=0.8078$ is less than 0.2 , which shows a good agreement within the model ${ }^{37}$. The results show that the best experimental conditions for alginate extraction from brown seaweed are: temperature $=92.91^{\circ} \mathrm{C}$, time $=110.81 \mathrm{~min}$, catalyst concentration $\left(\mathrm{Na}_{2} \mathrm{CO}_{3}\right)=2.60 \%$, with a maximum yield of alginate $=29.19 \%$.
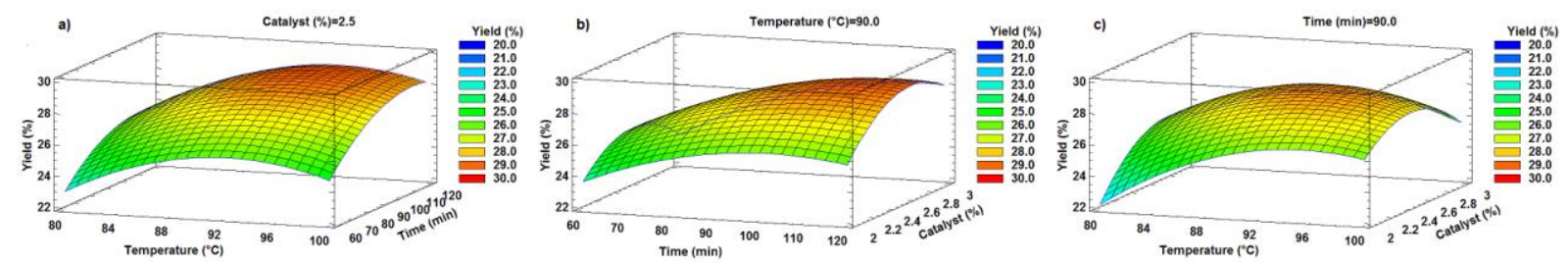

Figure 1. Response surface plot for the extraction of alginate from seaweed: (a) effect Temperature vs. Time, (b) effect Time vs. Catalyst, (c) effect Temperature vs. Catalyst

\subsection{Production of lactic acid from alginate}

The temperature has a strong effect on the yield of lactic acid, since as the former increases, the amount of lactic acid also increases (Fig. 2a), reaching a maximum point of $220^{\circ} \mathrm{C}$, which was the upper limit used in the present study. There is no experimental evidence to analyze what happens at a higher temperature. Concerning time (Fig. 2b), its influence is practically the same within the studied interval. It is recommended that in a new study, much shorter reaction times should be analyzed, since apparently, the reaction times used in the present study are too high, to such an extent that the production of lactic acid reached its limit value. Hydrothermal treatment times of 15, 30, and 45 minutes are suggested ${ }^{29}$. The effect of catalyst concentration (Fig. 2b and Fig. 2c) on the lactic acid yield is notable: the higher the catalyst concentration, the higher the amount of lactic acid produced until it reaches a saturation state. It is important to note that even without the catalyst, some 
lactic acid is formed due to the autoionizing property of the water, which acts as a catalyst and generates chemical reactions without the need to add external catalysts ${ }^{29}$.
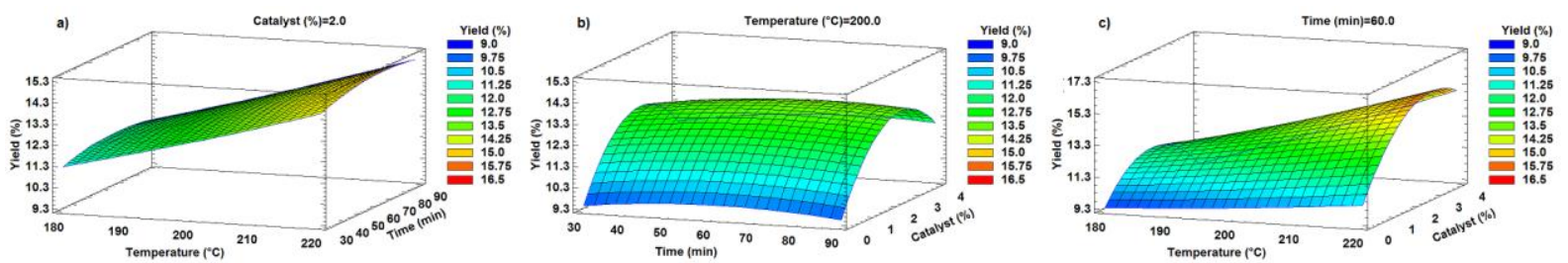

Figure 2. Response surface plot for the production of lactic acid from alginate: (a) effect Temperature vs. Time,

(b) effect Time vs. Catalyst, (c) effect Temperature vs. Catalyst

Table 2. Experimental conditions of variables and results obtained for the extraction of alginate from seaweed.

\begin{tabular}{|c|c|c|c|c|c|c|c|c|c|c|c|}
\hline \multirow{3}{*}{ Treat. } & \multicolumn{5}{|c|}{ Extraction of alginate from seaweed } & \multicolumn{6}{|c|}{ Analysis of variance } \\
\hline & \multirow{2}{*}{$\begin{array}{c}\mathrm{T} \\
\left({ }^{\circ} \mathrm{C}\right)\end{array}$} & \multirow{2}{*}{$\begin{array}{c}\mathrm{t} \\
(\min )\end{array}$} & \multirow{2}{*}{$\begin{array}{c}\text { C cat. } \\
(\%)\end{array}$} & $\begin{array}{l}\text { Yield } \\
(\%)\end{array}$ & $\begin{array}{l}\text { Yield } \\
(\%)\end{array}$ & \multirow[t]{2}{*}{ Source } & \multirow{2}{*}{$\begin{array}{l}\text { Sum of } \\
\text { squares }\end{array}$} & \multirow[t]{2}{*}{ df } & \multirow{2}{*}{$\begin{array}{l}\text { Mean } \\
\text { square }\end{array}$} & \multirow[t]{2}{*}{ F value } & \multirow[t]{2}{*}{$\mathrm{P}$ value } \\
\hline & & & & Exp. & Pred. & & & & & & \\
\hline 1 & 80 & 60 & 2.50 & 22.72 & 22.97 & Model & 63.29 & 9 & 7.03 & 34.40 & 0.0006 \\
\hline 2 & 80 & 90 & 2.00 & 22.19 & 22.16 & $\begin{array}{l}\text { A-Temp } \\
\text { (T) }\end{array}$ & 9.18 & 1 & 9.18 & 44.91 & 0.0011 \\
\hline 3 & 80 & 90 & 3.00 & 25.05 & 25.17 & $\begin{array}{l}\text { B-Time } \\
(\mathrm{t})\end{array}$ & 19.41 & 1 & 19.41 & 94.92 & 0.0002 \\
\hline 4 & 80 & 120 & 2.50 & 25.98 & 25.65 & $\begin{array}{c}\text { C- } \\
\text { Catalyst }\end{array}$ & 3.52 & 1 & 3.52 & 17.24 & 0.0089 \\
\hline 5 & 90 & 60 & 2.00 & 23.81 & 23.60 & $\mathrm{AB}$ & 0.1892 & 1 & 0.1892 & 0.9256 & 0.3802 \\
\hline 6 & 90 & 60 & 3.00 & 24.23 & 23.87 & $\mathrm{AC}$ & 2.82 & 1 & 2.82 & 13.81 & 0.0138 \\
\hline 7 & 90 & 90 & 2.50 & 28.20 & 28.43 & $\mathrm{BC}$ & 1.11 & 1 & 1.11 & 5.44 & 0.0669 \\
\hline 8 & 90 & 90 & 2.50 & 28.22 & 28.43 & $\mathrm{~A}^{2}$ & 12.00 & 1 & 12.00 & 58.68 & 0.0006 \\
\hline 9 & 90 & 90 & 2.50 & 28.87 & 28.43 & $\mathrm{~B}^{2}$ & 5.77 & 1 & 5.77 & 28.22 & 0.0032 \\
\hline 10 & 90 & 120 & 2.00 & 25.29 & 25.66 & $\mathrm{C}^{2}$ & 13.22 & 1 & 13.22 & 64.68 & 0.0005 \\
\hline 11 & 90 & 120 & 3.00 & 27.82 & 28.04 & Residual & 1.02 & 5 & 0.2044 & & \\
\hline 12 & 100 & 60 & 2.50 & 24.34 & 24.67 & $\begin{array}{c}\text { Lack of } \\
\text { Fit }\end{array}$ & 0.7316 & 3 & 0.2439 & 1.68 & 0.3945 \\
\hline 13 & 100 & 90 & 2.00 & 26.10 & 25.98 & $\begin{array}{l}\text { Pure } \\
\text { Error }\end{array}$ & 0.2906 & 2 & 0.1453 & & \\
\hline 14 & 100 & 90 & 3.00 & 25.60 & 25.63 & Cor Total & 64.31 & 14 & & & \\
\hline 15 & 100 & 120 & 2.50 & 28.47 & 28.23 & \multicolumn{3}{|c|}{ Std. Dev. $=0.4522$} & \multicolumn{3}{|c|}{$\mathrm{R}^{2}=0.9840$} \\
\hline \multirow{3}{*}{$\begin{array}{l}\text { Optimal } \\
\text { response }\end{array}$} & \multirow{3}{*}{\multicolumn{5}{|c|}{$\begin{array}{c}\text { Yield }(\%)=29.19 \\
\text { Temperature }\left({ }^{\circ} \mathrm{C}\right)=92.91 \\
\text { Time }(\min )=110.81 \\
\text { Catalyst }(\%)=2.60\end{array}$}} & \multicolumn{3}{|c|}{ Mean $=25.79$} & \multicolumn{3}{|c|}{ Adjusted $\mathrm{R}^{2}=0.9555$} \\
\hline & & & & & & C.V. & $\%=1.75$ & & \multicolumn{3}{|c|}{ Predicted $\mathrm{R}^{2}=0.8078$} \\
\hline & & & & & & $\begin{array}{l}\text { Regressi } \\
\quad \text { on } \\
\text { equation }\end{array}$ & \multicolumn{5}{|c|}{$\begin{array}{c}\text { Yield }(\%)=-217.739+3.706 * \mathrm{~T}+0.147881 * \mathrm{t} \\
+51.121 * \mathrm{C}-0.018028 * \mathrm{~T}^{2}+0.000728 * \mathrm{~T} * \mathrm{t}- \\
0.168035 * \mathrm{~T} * \mathrm{C}-0.001386 * \mathrm{t}^{2}+0.035223 * \mathrm{t} * \mathrm{C} \\
-7.5687 * \mathrm{C}^{2}\end{array}$} \\
\hline
\end{tabular}

The analysis of variance for lactic acid production (Table 3) indicates that temperature and catalyst concentration are the two variables with the significant influence (both variables present a p-value less than 0.05), while the reaction time is nonsignificant. The lack of fit is significant (p-value less than 0.05), and therefore, the second-order model by the Box-Behnken design could not fit a linear model. The regression coefficient $\mathrm{R}^{2}=0.9822$ is indicative of a good correlation within the experimental results. Nevertheless, the difference between the adjusted $\mathrm{R}^{2}=0.9502$ and the predicted $\mathrm{R}^{2}=0.7166$ is more significant than 0.2 , which indicates that the experimental data does not fit the model. The authors think that the considerable differences between the predicted and adjusted values of the model may be due to two reasons: the first, associated with the variable values of temperature and reaction times used 
in the experimental design, which were explained previously. The second, to the form of lactic acid quantification that was carried out employing a logarithmic calibration, as described later in section 3.3. Therefore, to determine the best HTT conditions on alginate to produce lactic acid, a new study considering temperature values greater than $220^{\circ} \mathrm{C}$ and reaction time less than 60 minutes should be conducted to understand the behavior of the HTT on alginate at these conditions.

However, even though the model has limitations, the use of microwaves in the HTT of alginate to produce lactic acid presents a positive effect. Comparing the present results with a similar study that does not contemplate the use of microwaves ${ }^{24}$, the application of temperature $=200^{\circ} \mathrm{C}$, time $=60$ minutes and catalyst concentration $(\mathrm{CaO})=2 \%$, allows obtaining a yield for lactic acid $=12.66 \%$. While using microwaves (present study), the yield of lactic acid = $13.32 \%$, which represents an increase of $5.2 \%$. Likewise, the maximum amount of lactic acid obtained with the use of microwaves is $15.71 \%$ in a time of 73.49 minutes, while without the use of microwaves, the maximum amount of lactic acid obtained is $14.66 \%$ in 360 minutes, which indicates a $7 \%$ higher yield in the production of lactic acid in a reaction time five times less.

Table 3. Experimental conditions of variables and results obtained for the extraction of alginate from seaweed.

\begin{tabular}{|c|c|c|c|c|c|c|c|c|c|c|c|}
\hline \multirow{3}{*}{ Treat. } & \multicolumn{5}{|c|}{$\begin{array}{c}\text { Production of lactic acid from } \\
\text { alginate }\end{array}$} & \multicolumn{6}{|c|}{ Analysis of variance } \\
\hline & \multirow{2}{*}{$\begin{array}{c}\mathrm{T} \\
\left({ }^{\circ} \mathrm{C}\right)\end{array}$} & \multirow{2}{*}{$\begin{array}{c}\mathrm{t} \\
(\min )\end{array}$} & \multirow{2}{*}{$\begin{array}{l}\text { C cat. } \\
(\%)\end{array}$} & $\begin{array}{l}\text { Yield } \\
(\%)\end{array}$ & $\begin{array}{l}\text { Yield } \\
(\%)\end{array}$ & \multirow[t]{2}{*}{ Source } & \multirow{2}{*}{$\begin{array}{l}\text { Sum of } \\
\text { squares }\end{array}$} & \multirow[t]{2}{*}{$\mathrm{df}$} & \multirow{2}{*}{$\begin{array}{l}\text { Mean } \\
\text { square }\end{array}$} & \multirow[t]{2}{*}{ F value } & \multirow[t]{2}{*}{$P$ value } \\
\hline & & & & Exp. & Pred. & & & & & & \\
\hline 1 & 180 & 30 & 2.00 & 10.97 & 11.25 & Model & 59.68 & 9 & 6.63 & 30.71 & 0.0007 \\
\hline 2 & 180 & 60 & 0.00 & 9.49 & 9.34 & $\begin{array}{l}\text { A-Temp } \\
\quad(\mathrm{T})\end{array}$ & 22.82 & 1 & 22.82 & 105.66 & 0.0001 \\
\hline 3 & 180 & 60 & 4.00 & 9.85 & 9.35 & B-Time (t) & 0.2664 & 1 & 0.2664 & 1.23 & 0.3172 \\
\hline 4 & 180 & 90 & 2.00 & 11.14 & 11.50 & $\begin{array}{l}\text { C-Catalyst } \\
\text { (C) }\end{array}$ & 10.10 & 1 & 10.10 & 46.79 & 0.0010 \\
\hline 5 & 200 & 30 & 0.00 & 9.57 & 9.43 & $\mathrm{AB}$ & 0.0169 & 1 & 0.0169 & 0.0783 & 0.7909 \\
\hline 6 & 200 & 30 & 4.00 & 11.17 & 11.38 & $\mathrm{AC}$ & 5.00 & 1 & 5.00 & 23.13 & 0.0048 \\
\hline 7 & 200 & 60 & 2.00 & 13.37 & 13.32 & $\mathrm{BC}$ & 0.0900 & 1 & 0.0900 & 0.4168 & 0.5470 \\
\hline 8 & 200 & 60 & 2.00 & 13.28 & 13.32 & $\mathrm{~A}^{2}$ & 0.0348 & 1 & 0.0348 & 0.1612 & 0.7047 \\
\hline 9 & 200 & 60 & 2.00 & 13.32 & 13.32 & $\mathrm{~B}^{2}$ & 0.4664 & 1 & 0.4664 & 2.16 & 0.2016 \\
\hline 10 & 200 & 90 & 0.00 & 9.70 & 9.50 & $\mathrm{C}^{2}$ & 20.97 & 1 & 20.97 & 97.10 & 0.0002 \\
\hline 11 & 200 & 90 & 4.00 & 11.90 & 12.04 & Residual & 1.08 & 5 & 0.2159 & & \\
\hline 12 & 220 & 30 & 2.00 & 14.86 & 14.51 & Lack of Fit & 1.08 & 3 & 0.3585 & 176.32 & 0.0056 \\
\hline 13 & 220 & 60 & 0.00 & 9.99 & 10.49 & Pure Error & 0.0041 & 2 & 0.0020 & & \\
\hline 14 & 220 & 60 & 4.00 & 14.82 & 14.97 & Cor Total & 60.76 & 14 & & & \\
\hline 15 & 220 & 90 & 2.00 & 15.29 & 15.00 & \multicolumn{3}{|c|}{ Std. Dev. $=0.4647$} & \multicolumn{3}{|c|}{$\mathrm{R}^{2}=0.9823$} \\
\hline \multirow{3}{*}{$\begin{array}{l}\text { Optimal } \\
\text { response }\end{array}$} & \multirow{3}{*}{\multicolumn{5}{|c|}{$\begin{array}{c}\text { Yield }(\%)=15.71 \\
\text { Temperature }\left({ }^{\circ} \mathrm{C}\right)=220.00 \\
\text { Time }(\min )=73.49 \\
\text { Catalyst }(\%)=2.97\end{array}$}} & \multicolumn{3}{|c|}{ Mean = 11.91} & \multicolumn{3}{|c|}{ Adjusted $R^{2}=0.9502$} \\
\hline & & & & & & C.V. & $=3.90$ & & \multicolumn{3}{|c|}{ Predicted $\mathrm{R}^{2}=0.7166$} \\
\hline & & & & & & $\begin{array}{l}\text { Regression } \\
\text { equation }\end{array}$ & $\begin{array}{r}\text { Yield }=1 \\
2.787 * \mathrm{C} \\
0 .\end{array}$ & +0 & $\begin{array}{l}-0.0751 \\
00243 * \mathrm{~T} \\
3 * \mathrm{~T} * \mathrm{C}- \\
475 * \mathrm{t} * \mathrm{C}\end{array}$ & $\begin{array}{l}7 * \mathrm{~T}+0.0 \\
+0.00010 \\
.000395 * \mathrm{t} \\
0.595 * \mathrm{C}^{2}\end{array}$ & $\begin{array}{l}7472 * \mathrm{t}- \\
* \mathrm{~T} * \mathrm{t}+ \\
+\end{array}$ \\
\hline
\end{tabular}

\subsection{Alginate characterization}

The FTIR spectra for reference alginate and extracted alginate from seaweed are presented in Figure 3, where a high correlation between the spectra of standard and extracted alginate can be evidenced, with small differences due to the level of purity of the obtained product. 


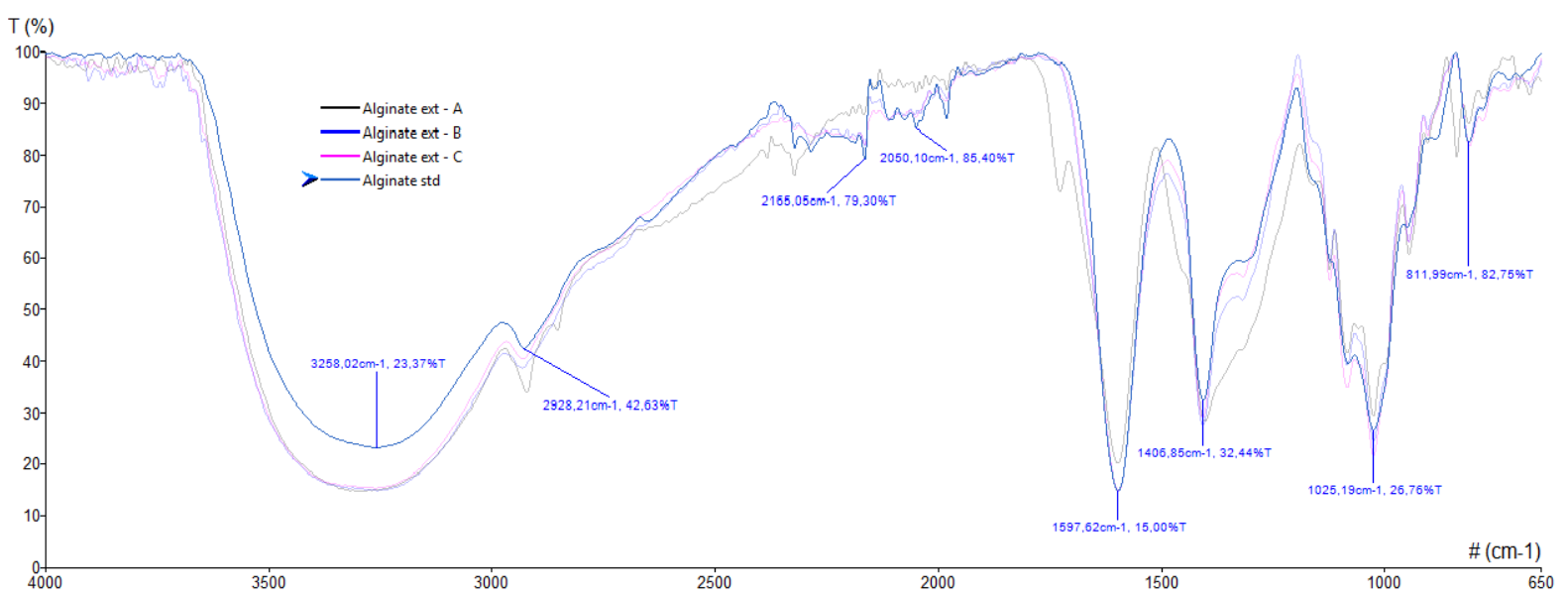

Figure 3. FTIR spectra for alginate reference and extracted samples

The values of the absorbance for the mannuronate $(\mathrm{M})$ peak at $1025 \mathrm{~cm}^{-1}$ and absorbance for guluronate $(\mathrm{G})$ peak at $1084 \mathrm{~cm}^{-1}$ are shown in Table 3 . It can be seen that the absorbance ratio of mannuronate $(\mathrm{M})$ /guluronate $(\mathrm{G})$ for all the samples is higher than 1.0 , indicating that the reference and extracted alginate from seaweed under the used methodology will form soft and elastic gels ${ }^{35}$. The thermal analysis by DSC and TGA applied to the reference alginate and extracted alginate shows a close similar thermal behavior: degradation is produced at a temperature of $225 \pm 5^{\circ} \mathrm{C}$, results identical to those previously reported ${ }^{38}$.

Table 3. Peak position, absorbance values, and absorbance ratio for characteristics mannuronate (M) and guluronate $(G)$ FTIR peaks in alginate samples.

\begin{tabular}{|c|c|c|c|c|c|}
\hline \multirow{2}{*}{ Sample } & \multicolumn{2}{|c|}{ Peak position $\left(\mathbf{c m}^{-\mathbf{1}}\right)$} & \multicolumn{2}{|c|}{ Absorbance } & ratio \\
\cline { 2 - 6 } & $\mathbf{M}$ & $\mathbf{G}$ & $\mathbf{M}$ & $\mathbf{G}$ & M/G \\
\hline Alginate reference & 1025.19 & 1081.67 & 0.573 & 0.402 & 1.426 \\
\hline Alginate extracted A & 1025.86 & 1084.23 & 0.531 & 0.379 & 1.400 \\
\hline Alginate extracted B & 1025.03 & 1084.45 & 0.610 & 0.405 & 1.507 \\
\hline Alginate extracted C & 1025.47 & 1084.5 & 0.664 & 0.457 & 1.451 \\
\hline
\end{tabular}

\subsection{Lactic acid quantification}

The topographic spectra for identification and quantification of lactic acid were produced using standard solutions of lactic acid between 0.35 and 3.0 $\%(w / v)$. The topographic signal for lactic acid used for calibration was located at retention time $(\mathrm{Rt}=14.70 \mathrm{~s})$ and drifted time $(\mathrm{Dt}=1.140 \mathrm{~ms})$, as can be seen at the top of Figure 4, where the logarithmic calibration curve based on the intensity signal is included. Based on the logarithmic regression, which generated a right correlation coefficient $\mathrm{R}^{2}=0.9983$, the amount of lactic acid in the experimental samples was quantified.

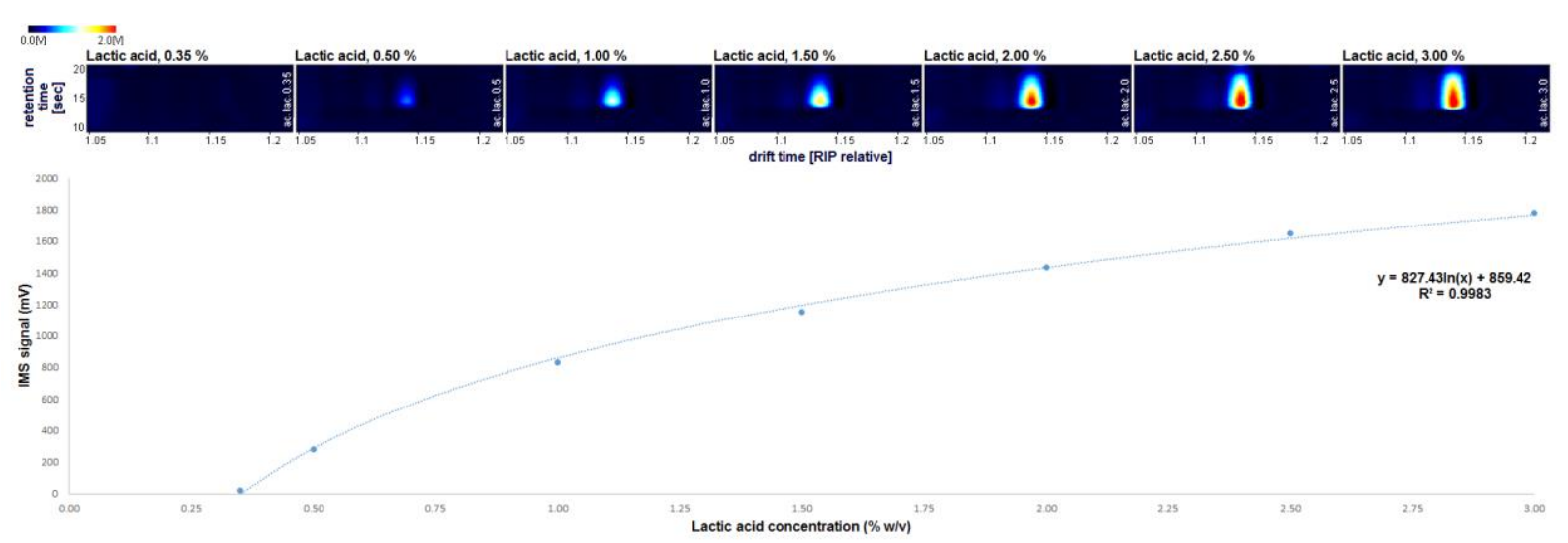

Figure 4. Topographic spectra for lactic acid standards, including logarithmic regression plot for IMS signal intensity vs. lactic acid concentration 


\section{Conclusion}

The extraction of alginate from brown seaweed and its subsequent transformation into lactic acid, using a microwave digester as a reactor in both cases, were developed favorably. The Response Surface Methodology obtained from the Box-Behnken design is useful for planning and applying designs with several variables and experimental responses. The application of this tool can significantly reduce the number of tests to be performed and, in turn, establish the best experimental conditions to achieve the highest experimental response; in this case, the extraction of alginate from brown seaweed and the production of lactic acid from the extracted alginate. Time, temperature, and catalyst concentration, in the indicated order, are the experimental parameters that play the most critical roles in the extraction of alginate. However, to produce lactic acid employing hydrothermal treatment on alginate, a new study with higher temperature conditions and shorter reaction times should be carried out to further explore the potential of seaweed as an attractive alternative for the chemical production of lactic acid.

\section{Funding Information}

The present study was carried out with the financial support provided by the Secretaría Nacional de Educación Superior, Ciencia, Tecnología e Innovación (SENESCYT-ECUADOR) through the agreement No. 20140077CI.

\section{Conflict of interest}

The authors declare that they have no conflict of interest.

\section{References}

1- F.A.C. Martinez, E.M. Balciunas, J.M. Salgado, J.M.D. González, A. Converti, R.P. de Souza Oliveira, Lactic acid properties, applications and production: a review, Trends in food science \& technology, 2013, 30, 70-83.

2- K. Okano, T. Tanaka, A. Kondo, In Lactic Acid: Bioprocessing of Renewable Resources to Commodity Bioproducts; ed. by B. Virenda, A. Kondo; John Wiley \& Sons: Hoboken, 2014, 353-380.

3- S.M. Ameen, G. Caruso, The Importance of Lactic Acid in the Current Food Industry. An Introduction, In Lactic Acid in the Food Industry, Springer: Berlin, 2017, 1-5.

4- D. Allen, H. Westerblad, Lactic acid: the latest performance-enhancing drug, Science, 2004, 305, 1112-1113.

5- L. Tin Sin, A. Rahmat, W. Rahman, Applications of Polylactic Acid, In Handbook of Biopolymers and Biodegradable Plastics: Properties, Processing, and Applications, Elsevier, Amsterdam, 2013, 11-54.

6- S. Concilio, P. Iannelli, L. Sessa, R. Olivieri,
A. Porta, F. De Santis, R. Pantani, S. Piotto, Biodegradable antimicrobial films based on poly (lactic acid) matrices and active azo compounds, Journal of Applied Polymer Science, 2015, 132,1-8.

7- A.M. Kinnersley, T.C. Scott, J.H. Yopp, G.H. Whitten, Promotion of plant growth by polymers of lactic acid, Plant Growth Regulation, 1990, 9 , 137-146.

8- M. Jamshidian, E.A. Tehrany, M. Imran, M. Jacquot, S. Desobry, Poly-Lactic Acid: production, applications, nanocomposites, and release studies, Comprehensive reviews in food science and food safety, 2010, 9, 552-571.

9- Q. Chen, J.D. Mangadlao, J. Wallat, A. De Leon, J.K. Pokorski, R.C. Advincula, 3D printing biocompatible polyurethane/poly (lactic acid)/graphene oxide nanocomposites: anisotropic properties, ACS applied materials \& interfaces, 2017, 9, 4015-4023.

10-J. Davis, Lactic Acid Market size worth over $\$ 6$ billion by 2024, Global Market Insights, Inc. http://globenewswire.com/newsrelease/2016/11/09/888221/0/en/Lactic-AcidMarket-size-worth-over-6-billion-by-2024Global-Market-Insights-Inc.html, 2016.

11-S.M. Ameen, G. Caruso, Chemistry of Lactic Acid, In Lactic Acid in the Food Industry; ed. by S.M. Ameen, G. Caruso; Springer: Berlin, 2017.

12-L. Serna-Cock, A. Rodriguez de Stouvenel, Producción biotecnológica de ácido láctico: estado del arte, Ciencia y tecnología Alimentaria, CYTA-Journal of Food, 2005, 5, 54-65.

13-Y. Wee, J. Kim, H. Ryu, Biotechnological production of lactic acid and its recent applications, Food Technology and Biotechnology, 2006, 44, 163-172.

14-C. Gao, C. Ma, P. Xu, Biotechnological routes based on the lactic acid production from biomass, Biotechnology advances, 2011, 29, 930-939.

15-B.F. Ustavshchikov, V.A. Podgornova, M.I. Farberov, M.S. Rusakova, L.V. Orlova, Synthesis of lactic acid from propylene (with $\alpha$-nitratopropionic acid as intermediate), Petroleum Chemistry, 1966, 6, 20-29.

16-W. Jeon, C. Ban, G. Park, J. Kim, H. Woo, D. Kim, Catalytic Conversion of Macroalgaederived Alginate to Useful Chemicals, Catalysis Surveys from Asia, 2016, 20, 195-209.

17-H. Kishida, F. Jin, Z. Zhou, T. Moriya, H. Enomoto, Conversion of glycerin into lactic acid by alkaline hydrothermal reaction, Chemistry Letters, 2005, 34, 1560-1561.

18-F. Chambon, F. Rataboul, C. Pinel, A. Cabiac, E. Guillon, N. Essayem, Cellulose hydrothermal conversion promoted by heterogeneous Brønsted and Lewis acids: remarkable efficiency of solid Lewis acids to produce lactic acid, Applied Catalysis B: Environmental, 2011, 105, 171-181.

19-W. Jeon, C, Ban, G. Park, T.K. Yu, J.Y. Suh, H.C. Woo, D.H. Kim, Catalytic hydrothermal 
conversion of macroalgae-derived alginate: effect of $\mathrm{pH}$ on production of furfural and valuable organic acids under subcritical water conditions, Journal of Molecular Catalysis A: Chemical, 2015, 399, 106-113.

20-S. N. Pawar, K.J. Edgar, Alginate derivatization: a review of chemistry, properties, and applications, Biomaterials, 2012, 33, 3279-3305.

21-J. S. Yang, Y.J. Xie, W. He, Research progress on chemical modification of alginate: A review, Carbohydrate polymers, 2011, 84, 33-39.

22-M. Fertah, A. Belfkira, M. Taourirte, F. Brouillette, Extraction and characterization of sodium alginate from Moroccan Laminaria digitata brown seaweed, Arabian Journal of Chemistry, 2017, 10, S3707-S3714.

23-A. Usman, S. Khalid, A. Usman, Z. Hussain, Y. Wang, Algal polysaccharides, novel application, and outlook, Algae-based polymers, blends, and composites, Elsevier, 2017, 115-153.

24-W. Jeon, C. Ban, G. Park, H.C. Woo, D.H. Kim, Hydrothermal conversion of macroalgae-derived alginate to lactic acid catalyzed by metal oxides, Catalysis Science \& Technology, 2016, 6, 1146-1156.

25-T. M. Aida, T. Yamagata, C. Abe, H. Kawanami, M. Watanabe, R.L. Smith, Production of organic acids from alginate in high-temperature water, The Journal of Supercritical Fluids, 2012, 65, 39-44.

26-D. Wang, E.J. Yun, S. Kim, D.H. Kim, N. Seo, H.J. An, J.H. Kim, N.Y. Cheong, K.H. Kim, Efficacy of acidic pretreatment for the saccharification and fermentation of alginate from brown macroalgae, Bioprocess and biosystems engineering, 2016, 39, 959-966.

27-W.L. White, P. Wilson, World seaweed utilization, Seaweed Sustainability Academic Press: Cambridge, 2015, 7-25.

28-A. Noreen, K.M. Zia, M. Jabeen, S. Tabasum, S. Rehman, N. Akram, Q. Wang, A Biorefinery Processing Perspective for the Production of Polymers, In Algae Based Polymers, Blends, and Composites, Elsevier, 2017, 335-370.

29-H.A. Ruiz, M. Conrad, S.N. Sun, A. Sanchez, G.J. Rocha, A. Romaní, I. Smirnova, Engineering aspects of hydrothermal pretreatment: From batch to continuous operation, scale-up and pilot reactor under biorefinery concept, Bioresource technology, 2020, 299, 122685.

30-N. Mosier, C. Wyman, B. Dale, R. Elander, Y.Y. Lee, M. Holtzapple, M. Ladisch, Features of promising technologies for pretreatment of lignocellulosic biomass, Bioresource technology, 2005, 96, 673-686.

31-H.A. Ruiz, R.M. Rodríguez-Jasso, M. Aguedo, Z. Kádár, Z. Hydrothermal pretreatments of macroalgal biomass for biorefineries, Algal biorefineries, Springer, Cham, 2015, 467-491.

32-H.A. Ruiz, R.M. Rodríguez-Jasso, B.D. Fernandes, A.A. Vicente, J.A. Teixeira, Hydrothermal processing, as an alternative for upgrading agriculture residues and marine biomass according to the biorefinery concept: a review. Renewable and Sustainable Energy Reviews, 2013, 21, 35-51.

33-D.C. Montgomery, Design and analysis of experiments, John Wiley \& Sons, 2017, 503-504.

34-K. Sakugawa, A. Ikeda, A. Takemura, H. Ono, Simplified method for estimation of composition of alginates by FTIR, Journal of Applied Polymer Science, 2004, 93, 1372-1377.

35-S. Sellimi, I. Younes, H.B. Ayed, H. Maalej, V. Montero, M. Rinaudo, M. Dahia, T. Mechichi, M. Hajji, M. Nasri, Structural, physicochemical and antioxidant properties of sodium alginate isolated from a Tunisian brown seaweed, International journal of biological macromolecules, 2015, 72, 1358-1367.

36-R. Rodríguez-Maecker, E. Vyhmeister, S. Meisen, A. Rosales-Martinez, A. Kuklya, U. Telgheder, Identification of terpenes and essential oils by means of static headspace gas chromatography-ion mobility spectrometry, Analytical and bioanalytical chemistry, 2017, 409, 6595-6603.

37-A. Mohammed, A. Rivers, D.C. Stuckey, K.Ward, K., Alginate extraction from Sargassum seaweed in the Caribbean region: Optimization using response surface methodology, Carbohydrate Polymers, 2020, 116419.

38-Z. Huang, X.H. Shi, W.J. Jiang, J. Zhang, Influence of Zeolite NaA on Thermogravimetric Behavior of Sodium Alginate for the Purpose of Processing Plastic Wastes, Advanced Materials Research, 2011, 291, 1875-1878. 